\title{
A INDÚSTRIA CULTURAL E O CARÁTER FICTÍCIO DA INDIVIDUALIDADE NA DEFINIĈ̃O DE CONSUMIDOR- COMUNIDADE GLOBAL
}

\author{
Loiane da Ponte Souza Prado Verbicaro* \\ Dennis Verbicaro Soares**
}

SUMÁRIO: Introdução; 20 esclarecimento como desencantamento do mundo; $3 \mathrm{~A}$ indústria cultural como processo de manipulação das massas; 40 caráter fictício da individualidade; 5 Conceito de consumidor no âmbito da comunidade global como consequência da indústria cultural; 6 Considerações finais; Referências.

RESUMO: O presente artigo tem por escopo realizar, por meio de pesquisa teórica, uma análise da conversão da indústria cultural em técnica de manipulação das massas com a consequente formatação do indivíduo e negação da sua individualidade e, nesse cenário, propõe-se a refletir sobre o conceito global de consumidor, diretamente afetado por esses influxos. Em linhas conclusivas, a pesquisa convalida a tese de que o conceito de consumidor ultrapassa fronteiras nacionais e assume uma dimensão internacional, tomando como fator legítimo de discriminação sua vulnerabilidade econômica transnacional diante de necessidades de consumo globais, estimuladas por uma indústria cultural a serviço do consumismo, a pretexto de anunciar uma maior emancipação e liberdade econômica do indivíduo.

PALAVRAS-CHAVE: Consumidor-Comunidade Global; Individualidade Fictícia; Indústria Cultural; Vulnerabilidade Transnacional.

\section{CULTURAL INDUSTRY AND THE FICTIONAL CHARACTER OF INDIVIDUALITY IN THE DEFINITION OF CONSUMER-GLOBAL COMMUNITY}

\footnotetext{
ABSTRACT: Current theoretical research analyzes the conversion of cultural industry into a technique of mass manipulation, followed by the formatation of the individual and the denial of his individuality. The global concept of the consumer directly affected by these influxes should be investigated. Research validates the thesis that

Doutora em Filosofia do Direito pela Universidade de Salamanca (Espanha); Docente da Graduação e do Programa de Pós-Graduação Stricto Sensu em Direito do Centro Universitário do Pará (CESUPA), Brasil; E-mail: loianeverbicaro@uol.com.br

${ }^{* *}$ Doutor em Direito do Consumidor pela Universidade de Salamanca (Espanha); Docente da Graduação e do Programa de Pós-Graduação Stricto Sensu em Direito da Universidade Federal do Pará (UFPA) e Docente da Graduação e Pós-Graduação Lato Sensu do Centro Universitário do Pará (CESUPA), Brasil.
} 
the concept of consumer is above national borders and becomes an international issue. Transnational economic vulnerability is its legitimate factor of discrimination in the wake of global consumption needs which are stimulated by the cultural industry at the service of consumerism under the guise of a greater emancipation and economic freedom of the individual.

KEY WORDS: Consumer-Global Community; Fictitious Individuality; Cultural Industry; Transnational vulnerability.

\section{LA INDUSTRIA CULTURAL Y EL CARÁCTER FICTICIO DE LA INDIVIDUALIDAD EN LA DEFINICIÓN DE CONSUMIDOR- COMUNIDAD GLOBAL}

RESUMEN: El presente artículo tiene por alcance realizar, por intermedio de investigación teórica, un análisis de la conversión de la industria cultural en técnica de manipulación de las masas con el consecuente formato del individuo y negación de su individualidad y, en ese escenario, se propone la reflexionar sobre el concepto global de consumidor, directamente afectado por esos influjos. En líneas conclusivas, la investigación convalida la tesis de que el concepto de consumidor ultrapasa fronteras nacionales y asume una dimensión internacional, tomando como factor legítimo de discriminación su vulnerabilidad económica transnacional delante de necesidades de consumo globales, estimuladas por una industria cultural a servicio del consumismo, a pretexto de anunciar mayor emancipación y libertad económica del individuo.

PALABRAS-CLAVE: Consumidor-Comunidad Global; Individualidad Ficticia; Industria Cultural; Vulnerabilidad Transnacional.

\section{INTRODUÇÃO}

$\mathrm{Na}$ era científica moderna e com o advento da técnica, a consequência das grandes invenções foi a ruína progressiva da cultura teórica e da autorreflexão do pensamento, a autodestruição do esclarecimento e a consequente concretização de experimentos erráticos. A tecnicização desencantou a vida, doutrinou o espírito humano a um só compasso, seja no trabalho industrial da fábrica, no cinema e na cultura, seja nas relações da vida individual e coletiva, gerando conformismo, aprisionamento e impotência como consequência lógica da sociedade industrial 
que, no âmbito das relações consumeristas, volta-se para um consumo, muitas vezes, irracional.

Nesse cenário em que o progresso reverte-se em regressão, o indivíduo se vê nulificado em face dos poderes econômicos que, ao mesmo tempo que anulam a individualidade (retração da subjetividade) transformando os indivíduos em meros seres genéricos, iguais uns aos outros e absolutamente substituíveis, elevam a produtividade econômica e o poder de dominação do homem e da técnica sobre a natureza a um nível jamais vislumbrado, comprometendo a sustentabilidade ambiental e acirrando a vulnerabilidade e hipossuficiência do consumidor em escala global.

O presente artigo tem por objetivo analisar, por intermédio de pesquisa teórica, a conversão da indústria cultural em técnica de manipulação das massas, com a consequente formatação do indivíduo e negação da sua individualidade, bem como compreender o impacto desses influxos na (re)definição do conceito de consumidor global, compreendido em seu alcance transnacional, que passa a ser diretamente afetado pela padronização dos hábitos de consumo em escala global, imposta pela indústria cultural e seus apelos propagandísticos e instrumentos de manipulação das massas.

A pesquisa realiza, do ponto de vista metodológico, um estudo que apresenta uma confluência entre a filosofia, a teoria política e o direito do consumidor, ao analisar, à luz da teoria crítica, especialmente, a partir das reflexões de Adorno, Horkheimer e Walter Benjamin, a indústria cultural e seus instrumentos de manipulação de massa que trazem impactos políticos às sociedades contemporâneas, notadamente ao viabilizar a manutenção do status quo e dos valores capitalistas, com repercussão na ampliação da vulnerabilidade do consumidor ante os mecanismos de padronização e imposição de necessidades de consumo.

A partir dessa realidade, delimita-se o problema da pesquisa, que é refletir acerca (do acirramento) da vulnerabilidade do consumidor global, sobretudo pela falta de marcos normativos claros quanto ao reconhecimento das práticas abusivas do fornecedor em escala mundial, a fim de se conceber instrumentos protetivos que o amparem em sua fragilidade diante da impositividade dos valores e modos de vida propagados pela indústria cultural.

É à luz dessas diretrizes que o artigo abordará a ideia de esclarecimento como desencantamento do mundo; o impacto da técnica proporcionado pelo avanço 
industrial e a indústria cultural como processo de manipulação de massas; o caráter fictício da individualidade a partir da padronização dos valores e modos de vida; o conceito de consumidor no âmbito da comunidade global como consequência da indústria cultural.

\section{O ESCLARECIMENTO COMO DESENCANTAMENTO DO MUNDO}

A ideia de esclarecimento presente na obra "Dialética do Esclarecimento", de Adorno e Horkheimer, expressa o processo de desencantamento do mundo, segundo o qual o homem radicaliza a angústia mítica e liberta-se do temor e da miopia ante o desconhecido mundo da natureza e de seus encantos. Seu propósito é substituir a imaginação pelo saber, livrando os homens do medo e da insegurança, investindo-lhes na posição de senhores. Com o processo de racionalização que prossegue na filosofia e na ciência, supera-se o desamparo em face ao misticismo das forças naturais. O mito converte-se em esclarecimento e a natureza, destituída de encanto, em mera objetividade. Esse movimento, no entanto, não se limita a um simples processo de ruptura ao mito.

A desmitologização ou a progressiva racionalização tiveram sua origem no próprio mito, notadamente na ideia, já presente no pensamento mitológico, de ascendência e superioridade do homem sobre a natureza inconsciente, a exemplo da inescapável compulsão à dominação da natureza já presente na obra "Odisseia", quando Ulisses, amarrado no mastro, evita a sedução do canto das sereias. Esse movimento encontra o seu termo na mitologização do esclarecimento sob a forma da ciência positiva, o que reflete na possibilidade de que o conhecimento, através da assimilação dos processos de controle da natureza, possa resultar, paradoxalmente, em uma mais completa forma de dominação do próprio homem plenamente civilizado, em que a dominação da natureza volta-se contra o próprio sujeito pensante.

Assim, o que se apresenta como triunfo da racionalidade objetiva, com a sujeição de todo ente ao formalismo lógico, tem por consequência a subordinação cega (e irracional) ao imediatamente dado. Destarte, o factual passa a ter a última palavra e o conhecimento passa a restringir-se à mera repetição do factual, convertendo-se em tautologia. "Quanto mais a maquinaria do pensamento subjuga 
o que existe, tanto mais cegamente ela se contenta com essa reprodução. Desse modo, o esclarecimento regride à mitologia da qual jamais soube escapar"”3.

Portanto, a dialética do mito e do esclarecimento acena à ideia de que o mito já é esclarecimento e o esclarecimento acaba por converter-se (e reverter-se) à mitologia. $\mathrm{O}$ aumento do poder passa a representar o substrato da dominação e a verdadeira alienação daquilo sobre o que se exerce o poder. $\mathrm{O}$ esclarecimento "comporta-se com as coisas como o ditador se comporta com os homens. Este conhece-os na medida em que pode manipulá-los. O homem de ciência conhece as coisas na medida em que pode fazê-las. É assim que seu em-si torna para-ele"04, confirmando a fé inabalável na capacidade do homem de dominar o mundo, bem como o retorno do esclarecimento à órbita do mito e a degeneração da fé em embuste e barbárie.

Esse pensamento, decerto, acena ao aprofundamento crítico da racionalização, que representa a desilusão das utopias e otimismo libertador da racionalidade que, em vez de permitir a construção de uma era verdadeiramente humana, propiciou o afundamento da humanidade esclarecida em uma nova espécie de barbárie, com a coisificação do homem, o distanciamento dos valores, a incapacidade de reflexão e a abstração da individualidade, ao se compreender o indivíduo como simples engrenagem do processo tecnológico, o que permitiu o seu desaparecimento enquanto ser individual diante do processo a que serve, convertendo o sonho de uma humanidade iluminada e emancipada em verdadeira desventura, com a ameaça de destruição precisamente daquilo que deveria e pretendia realizar: a ideia de homem em sua liberdade, em seu valor e em sua autonomia. Na era científica moderna e com o advento da técnica, o preço das grandes invenções foi, portanto, a ruína progressiva da cultura teórica e da autorreflexão do pensamento, a autodestruição do esclarecimento e a consequente concretização de experimentos erráticos.

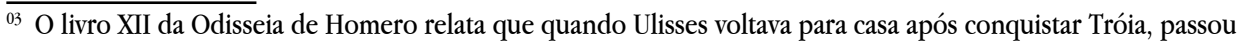
pela Ilha de Capri, a ilha das sereias, e sabendo do encanto destrutivo de suas canções (quem se deixa atrair por suas ilusões estaria condenado à perdição), tapou o ouvido dos tripulantes com cera e os obrigou a remar com todas as forças de seus músculos. Curioso para saber como era o canto, pediu que o amarrassem no mastro e por mais que quisesse atirar-se no mar, não conseguiria. Quando passou pela ilha, ouvindo a canção das sereias, impotente amarrado ao mastro, implorou para que seus homens o soltassem, mas como não podiam ouvi-lo, conseguiu sobreviver à promessa irresistível do prazer e da sedução. Segundo Adorno e Horkheimer, "as medidas tomadas por Ulisses quando seu navio se aproxima das Sereias pressagiam alegoricamente a dialética do esclarecimento". ADORNO, HORKHEIMER. Dialética do Esclarecimento. Rio de Janeiro: Zahar, 1985 , p. $8,15,38-41$.

${ }^{04}$ Ibid., p. 21.
} 
Nesse cenário, o indivíduo, esvaindo-se diante do maquinário a que serve, se vê, paradoxalmente, mais do que nunca provido e dependente dele, a ponto de aumentar a impotência das massas na exata medida do aumento da quantidade de bens a elas destinados, o que reflete, gradativamente, na elevação do padrão de vida material das classes inferiores, acompanhada de um embrutecimento da alma e da difusão hipócrita do espírito que se desperta (em face à enxurrada de informações direcionadas às massas) e idiotiza-se diante do enclausuramento imposto pelos novos padrões, muitos dos quais concebidos para estimular o consumo a partir dos valores projetados pela indústria cultural que cria modos, ideais de vida (mercadorias, música, cultura, cinema, entretenimento etc) a serem seguidos por uma sociedade massificada, padronizada e globalizada. Nesse cenário, o consumo passa a ser o constitutivo do reconhecimento, da inserção social e da própria existência (consumir é existir) nas sociedades contemporâneas que impõem hábitos comuns em escala global para fomentar a economia capitalista, sua produção e lucratividade.

\section{A INDÚSTRIA CULTURAL COMO PROCESSO DE MANIPULAÇÃO DAS MASSAS}

O impacto da técnica proporcionado pelo avanço industrial gerou uma mudança de mentalidade na vida, na arte, na cultura (superestrutura), que veio acompanhada do vazio de narrativa, da falta da troca de experiência e do sentido melancólico dessa constatação. Uma nova forma de miséria surgiu com esse monstruoso desenvolvimento da técnica, sobrepondo-se ao homem, gerando o desaparecimento do humano e "da imagem do homem tradicional, solene, nobre, adornado com todas as oferendas do passado, para dirigir-se ao contemporâneo nu, deitado como um recém-nascido nas fraldas sujas de nossa época” ${ }^{25}$.

Dentre as consequências advindas com o impacto da técnica, encontrase o desenvolvimento de mecanismos de controle das consciências individuais e coletivas, exercido pela imprensa, rádio e cinema, denominado de indústria cultural $^{06}$. Longe de sugerir a ideia de cultura produzida espontaneamente pelas massas, a indústria cultural impõe-se de cima para baixo, com a finalidade de

${ }^{05}$ BENJAMIN, Walter. Magia e Técnica, Arte e Política. Ensaios sobre Literatura e História da Cultura. São Paulo: Brasiliense, 1993, p. 115-116.

${ }^{06}$ ADORNO, Theodor. Indústria Cultural e Sociedade. São Paulo: Paz \& Terra, 2015. 
homogeneizar, adaptar e integrar as massas aos valores capitalistas de consumo. Para tanto, implementou um vasto processo de racionalização dos procedimentos de produção, padronização e difusão dos produtos culturais, em que os modelos são fornecidos a priori pela probabilidade de lucro, bilheteria e sucesso de mercado e não pela qualidade intrínseca da obra artística considerada em sua autonomia, em seu valor e em sua singularidade.

Nesse contexto, a técnica converte-se em psicotécnica, em artifícios de manipulação típicos da aparência fetichista das sociedades de massas. As pessoas transformam-se naquilo que o sistema, triturando-as, força-as a ser. Estão todos tão impregnados pelos esquemas da indústria cultural e sua exploração sistemática e programada de "bens culturais" para fins comerciais, que o que se vê é uma tentativa de fazer de si mesmo uma vida que corresponda, ipsis litteris, ao modelo apresentado pelos seus standards, donde se concebe a espontaneidade e a liberdade individual no plano da mera abstração do pensamento. Eis o triunfo da publicidade e da manipulação da indústria cultural, cujo resultado é a mimese compulsiva dos consumidores às mercadorias culturais da sociedade industrial e de consumo e a naturalização da sua linguagem a ponto de criar um repertório de gestos padronizados e estigmatizados.

A noção de estilo é, pois, contraditória por recusar a ordem posta cuja representatividade está presente nas convenções artísticas e, ao mesmo tempo, impossibilitar o afastamento de ditas convenções. Trata-se da dialética da ideia de estilo. Na indústria cultural há o desaparecimento dessa dialética. Compreendido como regra previamente fixada, o estilo, agora sem tensão, impõe ao produto cultural a adaptação às suas normas, permitindo a afirmação da ordem vigente e do sistema capitalista que as prescreve. Nesse sentido, percebe-se uma radicalização do estilo na indústria cultural, do qual toda tensão, dialética, negação e contestação do status quo foram excluídos, para ceder lugar à manipulação, padronização, empobrecimento e mercantilização dos padrões culturais.

Destarte, a indústria cultural relegou a cultura ao âmbito de produtividade do sistema capitalista, promovendo o esfacelamento da independência dos mecanismos de produção da obra de arte e do senso estético, integrando-a ao funcionamento da ordem posta. Com isso, a criação de necessidades de consumo obedece a critérios de mercado e acaba por impor predileções e forjar padrões de comportamento uniformes, neutralizando o potencial crítico do indivíduo, 
tornando-se a manifestação da lógica do mercado, com a dissolução da oposição entre cultura e mercado e a intensificação de seu uso como mecanismo psicotécnico de manipulação das massas. Consequência desse processo foi a homogeneização crescente dos indivíduos, exatamente análoga à ocorrida com os produtos da indústria cultural.

Segundo Gatti, no entanto, a experiência intelectual do pós-guerra na Alemanha provocou reformulações no pensamento de Adorno, notadamente ao perceber a descontinuidade entre a intenção de um produto da indústria cultural e o seu efeito real na consciência dos espectadores, ao verificar a possibilidade de reações não previstas vindas do público, o que acena à impossibilidade de controle total dos sentimentos das massas. Nesse sentido, "a tese da total integração do indivíduo à ideologia da indústria cultural, defendida na Dialética do Esclarecimento, fica relativizada" ${ }^{\prime 7}$. Com essas ideias, Adorno passa a admitir a possibilidade do uso crítico e esclarecedor, em certa medida, de determinados elementos da indústria cultural.

Na continuidade, o trabalho analisará o caráter fictício da individualidade a partir da ideia de indústria cultural como processo de manipulação das massas, o que atinge, no capítulo subsequente, o conceito de consumidor no âmbito da comunidade global, que se torna o alvo principal dos instrumentos e artifícios propagandísticos das sociedades capitalistas massificadas e da indústria cultural.

\section{O CARÁTER FICTÍCIO DA INDIVIDUALIDADE}

O modo concreto de ser do homem passou a ser precisamente a abstração. A padronização proporcionada pelo modo de produção das sociedades industriais gerou o indivíduo ilusório, a pseudoindividualidade ou o caráter fictício da subjetividade assumidos na era do liberalismo burguês com sua concepção de indivíduo como ser genérico, reforçada por um sistema político e jurídico amparados em um complexo de normas de estrutura geral, impessoal e abstrata que proporcionam um significado ideológico capaz de ocultar as reais desigualdades e diferenças entre os indivíduos.

Institui-se a ideia universal de que todos os homens são livres e iguais

${ }^{07}$ GATTI, Luciano. Theodor W. Adorno: Indústria Cultural e Crítica da Cultura. In: NOBRE, Marcos (org.). Curso Livre de Teoria Crítica. Campinas: Papirus, 2008, p. 92. 
(igualdade formal) para camuflar as reais desigualdades sociais, econômicas, culturais e educacionais concebidas pela vivência concreta dos homens, bem como para reduzir o individual à capacidade do universal de forjar os homens como seres abstratos e substituíveis, encobrindo o fato de que apenas pequena parcela da população poderia, de fato, ser livre e igual. Essa ideologia burguesa escamoteia as relações materiais concretas, substituindo-as por representações universais, formais e fictícias para reforçar a ilusão e a acomodação.

Esse encobrimento ideológico vela verdadeiras situações de ausência de liberdade, justiça e igualdade em uma ordem amparada e legitimada por representações fictícias, que provocam, na realidade, a negação das formas concretas desses valores, o que acena a um paradoxo: ao paradoxo da liberdade e igualdade projetadas e, ao mesmo tempo, negadas pelos Estados Liberais e sua ideologia capitalista. Na exata medida em que o liberalismo projeta-se como garantidor dos direitos individuais, da liberdade e igualdade, representando o verdadeiro marco da luta (da racionalidade) contra a (irracionalidade da) desigualdade de um sistema estamental, ele, igualmente, nega a concretização real desses valores ao apoiar-se em representações ilusórias e abstratas sobre a ideia de indivíduo.

Mesmo que se considere o intervencionismo do Estado na economia com a crise do liberalismo e a necessidade de preservação e legitimação do capitalismo em um contexto de questionamento de seus princípios excludentes, com a ampliação do conceito de igualdade (igualdade material), não se vislumbra a realização efetiva dessa igualdade, que perpassa, antes, pela necessidade de tratar os homens à luz de suas individualidades. Antes o contrário. De certa forma, a intervenção do Estado afastou o perigo de colapso do sistema, bem como acomodou eventuais classes sociais de exercer o papel de sujeitos revolucionários. Nota-se uma desmobilização da classe trabalhadora provocada tanto pelo controle ideológico realizado pela indústria cultural, como pela forma de exercício do poder político que impede, veladamente, a identificação clara de sua forma de dominação. Trata-se de uma conjugação de fatores (como a indústria cultural e o sistema político-econômico) que espraiou a dominação por toda organização social, política e cultural.

Seguindo com a ideia de negação da individualidade, "é porque os indivíduos não são mais indivíduos, mas sim meras encruzilhadas das tendências do universal, que é possível reintegrá-los totalmente na universalidade" ${ }^{\text {"8 }}$. Trata-se, ao

\footnotetext{
${ }^{08}$ ADORNO, HORKHEIMER. op. cit., 1985, p. 128.
} 
certo, de uma falaciosa individuação e de uma aparente liberdade como decorrência de ser o indivíduo o produto da aparelhagem econômica e social. Mas, ao mesmo tempo que negou, a sociedade burguesa igualmente concebeu e reforçou a ideia de indivíduo, ideia essa que nunca chegou a realizar-se plenamente, considerando-se a sua formatação e padronização aos modelos já concebidos.

Os padrões de vida, sucesso e beleza apresentados nas revistas e no cinema, nutrem-se da secreta satisfação de dispensar o esforço pela individuação, substituindo-o pelo esforço da imitação. Nesse sentido, a unicidade da subjetividade, bem como a liberdade e a autonomia individual não passam de um discurso retórico. A substituição "imposta" do individual pelo padrão estereotipado e heroificado há, no entanto, de tornar-se insuportável aos homens que nunca conseguirão alcançar o modelo artificial e de aparência dos heróis do cinema ou das modelos de capa de revista, resultando em negação da subjetividade, frustração e infelicidade por não ajustarem-se os indivíduos aos estereótipos rigorosamente projetados pela indústria cultural e divulgados pelos meios publicitários, que acabaram por transformar-se em verdadeiro "elixir da vida", com a repetição mecânica do produto cultural e seus slogans propagandísticos.

Nesse cenário, apresenta-se a denúncia de Guy Debord contra a espetacularização da política, da arte, da cultura e da vida. Sua crítica localiza-se no contexto da indústria do entretenimento associada à economia da abundância e da generalização dos meios de comunicação audiovisuais, em que se nota a colonização integral do homem e, inclusive, do ócio aparentemente liberado da produção industrial para apresentar-se com o objetivo da expropriação do tempo total da vida dos indivíduos, convertidos em massa de consumidores passivos e satisfeitos, em contempladores do espetáculo que assistem a sua própria alienação sem opor resistência alguma. Esse espetáculo é, ao mesmo tempo, o resultado e o projeto de reafirmação do modo de produção vigente. Trata-se do irrealismo da sociedade real, que constitui o modo atual e dominante de vida, cuja máxima expressão é a de um mundo invertido, em que o verdadeiro é apenas um "momento do falso". O espetáculo é a afirmação de toda vida humana como simples aparência ${ }^{09}$.

Seguindo essa crítica aos valores da sociedade capitalista, Debord denuncia o caráter tautológico do espetáculo que deriva do fato de que seus meios são, ao mesmo tempo, o seu fim. É o sol que nunca se põe no império da passividade

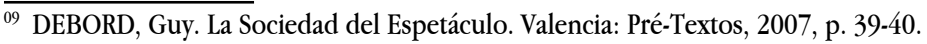


moderna e que recobre toda a superfície da terra e se sustenta indefinidamente em sua própria glória. $\mathrm{O}$ mundo real se transforma em meras imagens e as meras imagens se convertem em mundos reais, em uma realidade na qual apenas se permite aparecer na exata medida em que não se é ${ }^{10}$.

Nesse contexto de aparência, de vazio de sentido humano e de mecanização e repetição cotidiana da vida, dá-se uma total inversão da ideia de tempo como terreno do desenvolvimento humano. O tempo torna-se uma instância infinita de instantes iguais que se equivalem, uma medida meramente quantitativa de horas que se esvaem no cronômetro. O homem é nulificado pelo tempo que se finda, um sujeito historicamente condenado. O tempo não é o espaço da construção e criação livre do desenvolvimento humano, do porvir, do vir a ser. É puro determinismo inexorável.

É nesse cenário de formatação do indivíduo que o trabalho propõe-se a discutir o conceito de consumidor no âmbito da comunidade global, à luz da compreensão do impacto proporcionado pela indústria cultural na perda da individualidade do consumidor no mercado extraterritorial, a partir da redefinição direta ou subliminar do seu respectivo senso estético no momento de exercer suas escolhas de consumo, o que será analisado a seguir.

\section{O CONCEITO DE CONSUMIDOR NO ÂMBITO DA COMUNIDADE GLOBAL COMO CONSEQUÊNCIA DA INDÚSTRIA CULTURAL}

No âmbito das relações consumeristas, tem-se o conceito de consumidor comunidade global, que expressa a ideia de solidariedade e ilustra o rompimento com a tradição individualista do direito privado. Esse conceito sugere o compartilhamento da autoridade estatal com a sociedade civil, através da abertura e do estímulo à ocupação dos novos espaços políticos de deliberação, como também reposiciona a liberdade decisória da coletividade de consumidores em relação aos detentores dos meios de produção, seja através da difusão de novos deveres éticos aos fornecedores de produtos e serviços, seja através de instrumentos de proteção jurídico-políticos previstos na legislação para proteger o consumidor da massificação da mídia e da indústria cultural que corroem a identidade e a autonomia do sujeito.

\footnotetext{
${ }^{10}$ Ibid., p. 41, 133.
} 
A assimilação dos ideais solidários, nesse contexto, fortalece o consumidor, enquanto categoria política e passa a ser o ponto de partida para um modelo mais amplo de cidadania em uma democracia participativa. E, à luz desse pensamento, pretende-se estender essa perspectiva solidária para a tutela de uma coletividade transnacional, formada por um grupo de consumidores abstratamente considerado e ligado por um vínculo fático internacional com os grandes agentes econômicos do mercado de consumo, que, cada vez mais, exercem suas atividades muito além de um grupo restrito de países e que têm na inovação tecnológica e no apelo à publicidade mundial dos produtos e serviços o chamariz subjetivo e o liame psicológico necessários para atrair o interesse dos consumidores do mundo inteiro e, muitas vezes, simultaneamente.

Não há dúvida, por exemplo, de que smartphones e seus aplicativos, equipamentos e roupas de grandes fabricantes esportivos, eletrônicos, sites de comércio virtual, redes sociais, já alcançaram uma propagação em massa em escala mundial, despertando com a mesma intensidade desejos de consumidores do Brasil à Rússia, do Japão à Austrália, independentemente das sensíveis diferenças culturais entre esses países.

Também, é inegável o fato de que o comércio em escala mundial se despersonalizou e que os grandes grupos econômicos multinacionais desenvolveram ferramentas para forjar necessidades de consumo globais, estimular e vincular psicologicamente o consumidor a adquirir novos bens de consumo, sob a influência da indústria cultural concebida para moldar os gostos, predileções, senso estético e o próprio modelo ideal de qualidade de vida e realização pessoal do consumidor para o mundo globalizado. Essa habilidade é tão bem desenvolvida que o grau de penetração da abordagem transnacional não discrimina países ocidentais de orientais, desenvolvidos de subdesenvolvidos, de economia liberal daqueles intervencionistas, produzindo um verdadeiro diálogo universal.

Daí exsurge a identidade fática desse novo conceito, pois toda a coletividade, mundialmente considerada, estará exposta, através de ferramentas de um marketing agressivo, aos mesmos bens de consumo, nem sempre adequados, seguros, ou vendidos em condições transparentes e equitativas ao consumidor.

A globalização, portanto, gera uma profunda contradição conceitual na ideia de progresso, pois se por um lado o avanço tecnológico expandiu novas fronteiras para o conhecimento humano, a perda da racionalidade e da capacidade 
crítica do indivíduo em compreender e se proteger de um padrão cultural de consumo, que impõe comportamentos meticulosamente forjados pelos detentores dos meios de produção, acaba por minimizar os benefícios desse tão festejado progresso.

A indústria cultural emerge do desenvolvimento de mecanismos de controle das consciências individuais e coletivas, exercidos pelos meios de comunicação em massa, tais como rádios, televisão, cinema, jornais, revistas e etc, os quais não se preocupam em reproduzir fidedignamente a cultura espontânea produzida na sociedade, mas sim padronizar e adaptar as massas aos valores capitalistas de consumo, criando de forma explícita ou subliminar necessidades de consumo crescentes, através de um aprimorado processo de racionalização dos meios de produção, padronização, difusão e divulgação de bens de consumo como produtos culturais.

Modelos de consumo são apresentados no mercado, a pretexto de representarem os reais anseios do grupo, mas que, na verdade, se justificam pela maior probabilidade de lucro e sucesso de vendas, jamais pela qualidade intrínseca do bem em seu valor funcional, segurança ou singularidade.

Tem-se aí uma permanente necessidade de autoafirmação do consumidor, que busca imitar comportamentos e hábitos de consumo de uma realidade criada pela indústria cultural, que, obliquamente, funcionaliza as escolhas do consumidor de acordo com o padrão global de consumo do qual ele não participa como fonte indicativa de suas necessidades, mas apenas como integrante da massa subserviente de financiamento desse círculo vicioso de um consumismo inconsciente e irresponsável.

Neste particular, a tutela deste novo conceito de consumidor, compreendido a partir da ideia de comunidade global, se pauta no reconhecimento de uma soberania solidária entre os Estados, através de políticas comuns para dirimir os conflitos de consumo inerentes à exposição transnacional de práticas abusivas dos grandes grupos econômicos, que acabaram por neutralizar o potencial crítico do indivíduo, minando a liberdade de escolha, acirrando sua vulnerabilidade no mercado de consumo.

Nesse particular, precisa é a análise de Newton de Lucca ${ }^{11}$, quando afirma que:

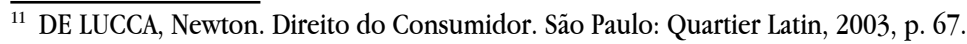


Os economistas contemporâneos modernos estão em vias de liquidar a noção clássica de mercado, sobre a qual se fundou toda a análise econômica não-marxista desde Adam Smith. Na concepção tradicional, o mercado é sempre organizado em função do consumidor, cujas decisões fundamentam, em última análise, a correspondência entre ofertas e demandas, num regime de produção essencialmente concorrencial. A situação de monopólio é considerada excepcional e combatida como autêntica aberração. Hoje, reconhece-se que o mercado de bens, serviços e de força-trabalho é formado pelas decisões do conjunto de empresas dotadas de poder econômico, ao qual se submetem todas as demais unidades, pequenas ou médias. As relações que se estabelecem entre esses setores, o nuclear e o periférico, são em tudo análogas ao relacionamento entre países desenvolvidos e subdesenvolvidos. O poder econômico, portanto, é a regra e não a exceção. Ora, a finalidade última desse poder, do qual todos nós dependemos, não pode ser apenas, nem principalmente, a produção e partilha de lucros entre proprietários e capitalistas; não deve ser, tampouco, assegurar ao empresário um nível de elevada retribuição econômica e social. O poder econômico é uma função social, de serviço à coletividade.

Durante muito tempo o conceito de mercado de consumo foi definido a partir das fronteiras nacionais, a ponto de se excluir a tutela consumerista na hipóteses de produtos adquiridos no exterior mediante compra direta ou virtual, sob a premissa de que o mesmo não foi planejado e concebido para as particularidades do mercado brasileiro, daí porque eventuais vícios e defeitos não poderiam ser imputados ao fornecedor, pois como foram adquiridos no exterior, seus padrões de adequação e segurança seriam outros, alterando, muitas vezes, a projeção de durabilidade e, por conseguinte, afastando a responsabilidade daquele pela ausência de padrões de previsibilidade objetiva do risco.

Aliás, a própria Lei 8078/1990 (Código de Defesa do Consumidor) já propagava essa ideia pela excludente de responsabilidade civil pelo defeito do produto, prevista no artigo 12 , parágrafo $3^{\circ}$, I, quando dispõe que o fabricante, o construtor, o produtor ou importador só não serão responsabilizados quando provarem que não colocaram o produto no mercado. Percebe-se, pela leitura do dispositivo legal, uma clara limitação geográfica do conceito de mercado, algo incompatível, nos dias atuais, com o próprio alcance do comércio eletrônico, da publicidade transnacional, das redes sociais e etc.

O falseado padrão de qualidade de vida imposto pelo consumismo é uma utopia inalcançável, mas que tem, cada vez mais, influenciado o indivíduo a 
reproduzir comportamentos estereotipados, alienando-se do mundo real, negando sua subjetividade em uma constante imitação do outro, tornando-se, portanto, um consumidor permanentemente frustrado e infeliz por não conseguir satisfazer suas mais variadas necessidades artificiais criadas pela indústria cultural.

A indústria cultural convalida as ideologias dominantes, favorece a funcionalização do mercado de consumo global de acordo com os interesses dos detentores dos meios de produção, forjando "sujeitos genéricos" e provocando uma vulnerabilidade transnacional, a pretexto de exercer um papel simplificador dos conflitos e contradições eventualmente manifestadas na comunidade internacional.

Esse novo conceito de consumidor-comunidade global é representativo, inclusive, de uma quarta dimensão de direitos fundamentais, inerentes à proteção do consumidor no âmbito mundial, cuja identidade estaria na existência de uma proteção jurídica comum frente aos abusos praticados em escala global que não atingem um grupo determinado de pessoas, mas toda a comunidade internacional a um só tempo, daí porque é, também, um conceito difuso, indivisível e de titularidade indeterminada.

Imagine-se a seguinte situação: um fabricante de smartphones lança, simultaneamente, no mundo inteiro e através de campanha publicitária em um grande evento esportivo global (Jogos Olímpicos ou Copa do Mundo) seu novo produto, informando acerca de qualidades inexistentes ou mesmo expondo a todos a um produto inseguro em determinadas condições climáticas, o que é desconhecido do fabricante ou eloquentemente omitido, para não prejudicar a oportunidade de venda e a imagem de confiabilidade da marca.

Posteriormente, em vários países europeus, ocorrem acidentes de consumo, vitimando sujeitos individuais ou grupos específicos de consumidores. Nesse caso, por mais que seja possível a identificação de danos concretos ou de países específicos em que os eventos danosos ocorreram, nos quais haverá, por certo, a devida responsabilização penal, civil e administrativa do fabricante no âmbito do direito nacional, ou mesmo no âmbito da União Europeia, pela transgressão de qualquer de suas diretivas, não se pode negar o alcance difuso e internacional da prática abusiva e, para preencher essa lacuna conceitual, emerge o novo conceito de consumidor comunidade-global, forjado a partir da exposição potencial de todos os consumidores.

Nesse caso, será mais que prudente, sábia e conveniente a aplicação de novas diretrizes de segurança em face do fornecedor e sanções não apenas no 
âmbito do espaço comum europeu, mas também no âmbito dos demais continentes, minimizando o risco de novos acidentes, evitando a recorrência da conduta ilícita.

Essa preocupação tem ocorrido com maior frequência no caso do recall de automóveis, pois a própria mobilização da sociedade tem obrigado os fabricantes a compartilharem as experiências negativas e adotarem as mesmas medidas de prevenção em razão do mesmo produto em países diferentes daquele em que o defeito foi evidenciado. Tem-se aí a expressão da proteção global do consumidor.

O Direito do Consumidor é um dos ramos mais prolíferos em temas juspolíticos que revelam interesses nacionais e transnacionais. A globalização eliminou fronteiras entre pessoas de diferentes países que, como regra, não possuem muitas semelhanças, mas que, agora, estão padronizadas por necessidades de consumo comuns, divulgadas diariamente e que são assimiladas como novos padrões culturais de beleza, funcionalidade e, por que não dizer, de aceitação e status social.

A identidade global entre "estranhos" estaria no liame fático que interliga os detentores dos meios de produção às necessidades de consumo dos destinatários dos bens colocados no mercado de consumo em escala mundial.

$O$ fator legítimo de discriminação, ou seja, a justificativa para o tratamento jurídico diferenciado do consumidor no plano internacional estaria no reconhecimento de sua vulnerabilidade à indústria cultural forjada para atender às necessidades expansionistas do consumismo em escala global e para estimular a fascinação daquele com sua nova liberdade econômica e com todas as inovações tecnológicas, fruto de um obsoletismo maliciosamente planejado.

Em outras palavras, aquele que não participa ativamente da sociedade da informação e não cede às pressões psicológicas desse novo modelo consumista estaria fadado à marginalidade e à exclusão econômica, o que faria do consumidor mundial alguém em constante processo de autoproteção, pois vítima de uma espécie de bullying social e econômico.

Esse consumidor global, para ser bem aceito no grupo ou para sentir a pseudo felicidade decorrente de seu novo status de proprietário de bens com apelo mundial, muitas vezes decidirá por impulso, perderá a racionalidade no momento de realizar transações econômicas, se colocará em situação de superendividamento e, ao final, permanecerá infeliz, pois sua carência emocional não será aplacada pelo consumismo irresponsável. 
Destaque-se que essa infelicidade cíclica, conquanto seja interrompida por momentos de euforia pela aquisição de novos bens de consumo, irá, paulatinamente, minar a capacidade decisória e, principalmente, o equilíbrio financeiro do consumidor, gerando um estado de dependência pernicioso à indústria cultural.

Esse fenômeno ocorrerá, independente da nacionalidade ou capacidade financeira do consumidor, pois será preferível a aquisição contínua e irresponsável dos novos bens de consumo e o consequente endividamento daí decorrente (fenômeno esse também compreendido sob a égide da globalização) ao ostracismo cultural de não usufruir o bem e, o que é pior, de não ser visto pelos demais como "igual" na moda de consumo que lhe foi apresentada como padrão cultural a ser seguido.

Não há dúvida de que aspectos culturais e econômicos são os grandes condicionantes da humanidade e, na sociedade globalizada, acabaram se fundindo em um modelo de consumismo irresponsável e que justificou a necessidade de uma proteção mais elástica do consumidor, destarte, no âmbito da comunidade internacional.

Nos dizeres de Cláudia Lima Marques ${ }^{12}$ :

A atual globalização - como nunca antes - modificou nosso sentimento de tempo e espaço: tudo está mais perto, tanto as nações, quanto as pessoas, tudo mais rápido e urgente, fugaz! O Direito Internacional Privado, direito dos conflitos e dos diálogos das leis no espaço, ganhou assim conjuntura e atualidade. E, parece-me, a sua imagem de pessoa também restou alterada.

A fascinação do consumidor globalizado com este modelo é evidente, o que convalida a sua própria vulnerabilidade e necessidade de proteção jurídica diferenciada, pois não são raras as notícias de pessoas que passam dias na fila, em condições climáticas extremas, para serem os primeiros a adquirirem os novos modelos de bens de consumo da moda, muitas vezes em preços estratosféricos e sem grandes ou sensíveis diferenças em relação aos modelos anteriores, apenas para aplacarem uma ansiedade de consumo doentia, havendo aqueles, inclusive, que se aventuram no mercado da pirataria e da falsificação para serem vistos e se autorreconhecerem como parte integrante da mesma tendência estética de consumo.

\footnotetext{
${ }^{12}$ MARQUES, Cláudia Lima. A proteção dos consumidores em um mundo globalizado: Studium Generale sobre o consumidor como Homo Novus. Revista de Direito do Consumidor, São Paulo, ano 22, v. 85, jan.-fev./2013, p. 46.
} 
Essa realidade provoca a necessidade de mudanças não apenas no plano do direito nacional, no que o Brasil está bem amparado pelo microssistema normativo de proteção do consumidor, mas que deverá ocorrer também no plano do direito internacional privado.

O papel do direito internacional privado não se limita à mera identificação de elementos de conexão entre normas de direito estrangeiro para uma situação conflituosa plurilocalizada. É preciso legitimar as escolhas e preceitos a partir de fontes universais, ou seja, é preciso dar uma nova roupagem ao direito internacional, que deixa de selecionar, em meio às normas em conflito de países diferentes, apenas uma que seria a mais adequada ao caso, para priorizar a formação de um direito global e uniforme, devidamente recebido no plano normativo, sobretudo em matéria de consumo no ambiente globalizado ${ }^{13}$.

A principal referência histórica no Direito Internacional acerca da proteção consumerista foi a Resolução n ${ }^{\circ}$ 1985/1999 da ONU, que espelhava um texto universal para o reconhecimento jurídico do consumidor como categoria merecedora de tutela normativa diferenciada. Da mesma forma, a International Law Association, em seu $74^{\circ}$ Congresso, reafirmou a importância do Direito Internacional Privado para alavancar a proteção do consumidor aqui compreendido como hiper-consommateur, mas nada suficientemente eficaz para garantir a tão almejada segurança jurídica no plano internacional.

No Brasil, devido à incipiência das normas de proteção internacional do consumidor, o Código de Defesa do Consumidor, que é uma norma de ordem pública e interesse social, assumiu, mesmo que obliquamente, esta função de controle de práticas abusivas que se verificam além das fronteiras nacionais. Todavia, nos PLS 281/2012 e 283/2012, em especial no que pertine ao comércio eletrônico e ao tema do superendividamento, respectivamente, a questão está sendo melhor colocada, embora ainda dependa de aprovação no Congresso Nacional ${ }^{14}$.

Nesse particular, pelo Extrato do Relatório-Geral da Comissão de Juristas do Senado Federal para atualização do Código de Defesa do Consumidor, há nítida preocupação com o superendividamento como um fenômeno do mundo globalizado e que precisa ser inserido em uma estrutura normativa capaz de eliminar suas causas e mitigar suas consequências.

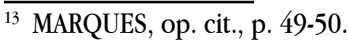

${ }^{14}$ MARQUES, op. cit., p. 59.
} 
Esse reforço da dimensão inclusiva do Código de Defesa do Consumidor, por meio da diretriz de inclusão social e probidade destes Anteprojetos de leis, dá-se seja no sentido de criar instrumentos e normas novas para prevenir o superendividamento da pessoa física de boa fé; seja no sentido de promover o acesso ao crédito responsável e à educação financeira do consumidor; seja no sentido de reforçar as iniciativas pioneiras de tratamento global em audiências conciliatórias com todos os credores para elaborar e aprovar planos de pagamento das dívidas dos consumidores superendividados e facilitar remédios judiciais, em caso de impossibilidade de acordo; seja ao estabelecer limites à publicidade do crédito, práticas comerciais e ao assédio de consumo em geral, protegendo em especial consumidores idosos, jovens, crianças, analfabetos, mantendo e expandindo as listas de práticas e cláusulas abusivas, sem mudança na sistemática do microcódigo, seja protegendo o consumidor nas suas contratações a distância, nacionais e internacionais, de forma a garantir não somente sua liberdade de escolha destes produtos e serviços, mas sua igualdade nestas contratações, cada vez mais importantes e simbólicas da inclusão dos brasileiros na sociedade globalizada de consumo do século XXI ${ }^{15}$.

\section{Ainda em 2012, a International Law Association fez sua primeira} Resolução sobre a tutela consumerista no plano internacional (Resolução no 4/2012), através da qual foram consolidados os seguintes princípios: a) reconhecimento da vulnerabilidade do consumidor no mercado de consumo internacional; b) proteção mais favorável ao consumidor; c) transparência e repressão aos abusos; d) proteção ao crédito responsável; e e) incentivo à participação institucional dos consumidores na regulação da legislação e, neste particular, não há dúvida da conexão com a lógica da solidariedade emancipatória, que naturalmente exige um maior envolvimento cívico do consumidor no contexto político-decisório ${ }^{16}$.

Nesse sentido, pode-se dizer que existem indícios de uma mudança juspolítica nas proposições brasileiras junto aos organismos internacionais, como a OEA e o Mercosul, o que revela o reconhecimento do Direito Internacional Privado como um instrumento de inclusão dos consumidores e de Estados no mercado global $^{17}$, como exigência normativa de proteção do consumidor ante os apelos da indústria cultural típicos da atual sociedade capitalista massificada.

\footnotetext{
${ }^{15}$ BENJAMIN, Antônio Herman; MARQUES, Cláudia Lima. Extrato do Relatório-Geral da Comissão de Juristas do Senado Federal para atualização do Código de Defesa do Consumidor. Revista de Direito do Consumidor, São Paulo, ano 23, v. 93, maio-jun./2014, p. 308.

${ }^{16}$ Ibid., p. 60.

${ }^{17}$ MARQUES, op. cit., p. 46, 62.
} 


\section{CONSIDERAÇÕES FINAIS}

Com a difusão dos valores da economia mercantil burguesa, o horizonte sombrio do mito é aclarado pela luz da racionalidade, cujos raios gelados amadurecem a sementeira da nova catástrofe. Sob o amparo da dominação, o trabalho humano tendeu a se afastar do mito, voltando a cair sob o seu influxo, levado pela mesma lógica de dominação. Nesse sentido, verifica-se que não é o malogro do progresso, mas exatamente o progresso bem-sucedido que é o responsável pelo seu próprio oposto. A maldição do progresso irrefreável acaba sendo, segundo Adorno e Horkheimer, a irrefreável regressão.

Pari passu ao desenvolvimento da técnica, da racionalidade e do progresso, e mesmo para alcançar a funcionalidade do sistema, representado pela sociedade tecnológica, pôs-se em marcha a indústria cultural, capaz de impor valores e modelos de comportamentos uniformes insuscetíveis de emancipar ou estimular a criatividade e a liberdade, mas tão-só de realizar perfidamente o homem como ser genérico, passivo e submisso à lógica da engrenagem de dominação da natureza em prol do progresso tecnológico. Nota-se, nesse contexto, uma sociedade paralisada, na qual o sistema, compreendido em sua totalidade (sistema político, econômico, social, cultural) é concebido para eliminar a crítica e a oposição. O resultado disso foi o universo unidimensional de ideias e comportamentos, nos quais as verdadeiras aptidões para o pensamento crítico foram anuladas.

No enlace entre infraestrutura e superestrutura estão presentes os elementos para a manutenção do status quo. Os instrumentos ideológicos de manipulação das massas e de negação da individualidade acenam à perda da autonomia e da capacidade das massas formatadas de representar uma oposição ao sistema vigente, demonstrando a sua inaptidão para conter minimamente a crescente tecnologização ou racionalidade tecnológica, o que reforça a sua aceitação acrítica aos valores vigentes e o ciclo de dominação e retração da subjetividade que o indivíduo está condicionado a viver.

$O$ apego a uma individualidade artificial, que sugere uma responsabilidade apenas para consigo mesmo são ideias difundidas pelos atuais e cada vez mais convincentes modelos de convencimento publicitário de massas, em detrimento da singularidade individual de cada um. Em outras palavras, a lógica do mercado atual 
suscita a "descartabilidade" dos homens ${ }^{18}$ a partir da própria superficialidade de suas predileções, em regra, forjadas pelo próprio mercado.

A sociedade de consumo acostumou-se com o obsoletismo planejado, pois a ideia de durabilidade de bens de consumo não agrada ao mercado, que sempre fomentou a circulação e a substituição contínua desses bens, gerando uma espécie de consumismo irresponsável, traço característico do consumidor no plano global.

$\mathrm{Na}$ realidade atual, a insatisfação pessoal com a vida e as carências emocionais e sociais podem ser facilmente compensadas pela satisfação e pelo prazer de comprar, mesmo que compulsivamente. A ideia por trás desse hábito não é satisfazer uma necessidade real de consumo, normalmente associada à utilidade daquele bem para uma finalidade específica, mas sim, uma necessidade aparente, às vezes relacionada à autoafirmação do sujeito, concebida pela criatividade publicitária, que cumprirá uma finalidade ilusória e, naturalmente, passageira.

A cultura líquido-moderna não se percebe mais como uma cultura do aprendizado e do acúmulo. Agora, como descreve Bauman, se revela uma cultura do desengajamento, da descontinuidade e do esquecimento ${ }^{19}$. A cultura do desperdício ${ }^{20}$, do lixo e do uso irracional dos recursos naturais para aplacar as carências consumistas de um mercado global, sempre ávido por novidades e novos padrões estéticos a serem seguidos, vai reduzindo, cada vez mais, a individualidade humana e sua capacidade plena de fazer escolhas não apenas de consumo, mas também no âmbito profissional e afetivo.

Nesse sentido, veja-se o surgimento de novos agentes do mercado, como, por exemplo, o coach e o personal stylist. O primeiro tem a função de orientar um determinado profissional a fazer escolhas corretas para ser bem sucedido na profissão. O segundo definirá o modo de vestir, o que comprar e até mesmo a "melhor" maneira de arrumar os sapatos no closet, ou mesmo a mala de viagem. Em outras palavras, fazer escolhas pessoais e profissionais já pode ser terceirizado mediante o pagamento. Ora, se no aspecto pessoal e profissional as escolhas deixaram de ser individuais e autênticas em prol de um modelo padronizado, no âmbito das predileções de consumo parece sedutora a ideia de que o mercado se substitua ao consumidor em suas angústias, riscos e mesmo em sua liberdade e decida por ele.

\footnotetext{
${ }^{18}$ BAUMAN, Zygmunt. A ética é possível num mundo de consumidores? Rio de Janeiro: Zahar, 2011, p. 63.

${ }^{19}$ BAUMAN, Zygmunt. Vida líquida. Rio de Janeiro: Zahar, 2009, p. 83.

${ }^{20}$ BAUMAN, Zygmunt. Vida para o consumo: a transformação das pessoas em mercadoria. Rio de Janeiro: Zahar, 2008 , p. 31.
} 
É nesse cenário que se insere a compreensão do conceito de consumidorcomunidade global como um desafio normativo extraterritorial, de modo a melhor blindar a capacidade decisória do consumidor, minimizando o poder de persuasão da industrial cultural em seus hábitos de consumo, resgatando uma subjetividade autêntica e não forjada pela despersonalização da atividade empresarial em escala global.

É fundamental o desenvolvimento de redes de comunicação, acesso à informação qualificada, mudanças sociais, mobilidade geográfica, controle da publicidade, maior nível de educação e, sobretudo, consciência crítica da população para conhecer e ocupar os espaços políticos de deliberação.

Aos consumidores será propiciado um sistema com acesso à oportunidade para formular suas preferências e indicar os melhores caminhos para concretizar suas necessidades de consumo, podendo compartilhá-las com os demais consumidores, agentes econômicos do mercado e com as autoridades públicas, seja individualmente, seja no plano coletivo. Nesse caso, a tutela coletiva internacional funciona como uma importante ferramenta de modernização social, de modo que tais preferências e necessidades sejam sopesadas e discutidas em condições de igualdade no debate político.

Em outras palavras, é justamente essa igual capacidade de participação que forjará a identidade cívica do consumidor em todas as suas vertentes conceituais: concreto, abstrato, individual, coletivo, por equiparação e, em uma perspectiva ainda mais contemporânea, também através do conceito de comunidade global, que eleva esse mesmo consumidor a um patamar de consideração normativa internacional, ao identificar sua dimensão globalizante, não sujeita às fronteiras de uma soberania exclusiva.

Em linhas conclusivas, a coletividade transnacional será composta por um grupo de consumidores abstratamente considerado e ligado por um vínculo fático internacional com empresas multinacionais, devendo-se aprimorar sua maior capacidade de intervir na formatação do mercado de consumo, impingindo ao segmento empresarial o ônus de se adaptar às suas necessidades e não o contrário, rompendo-se com a tradicional manipulação da vontade do consumidor, que acabaria não desenvolvendo suas necessidades de consumo autênticas, pois todas ou, na melhor das hipóteses, a grande maioria delas seria forjada pelos detentores dos meios de produção. 
Isso tudo, portanto, ratifica e convalida a tese de que a definição do conceito de consumidor ultrapassa fronteiras nacionais e assume uma dimensão internacional, tomando como fator legítimo de discriminação sua vulnerabilidade econômica transnacional diante de necessidades de consumo globais, estimuladas por uma indústria cultural a serviço do consumismo, a pretexto de anunciar uma maior emancipação e liberdade econômica do indivíduo.

O conceito de consumidor-comunidade global vai ao encontro dessa identidade fática, mas precisa ser modulado por normas claras de um novo direito internacional privado, não mais sujeito às peculiaridades e diferenças de uma ou outra legislação nacional, mas que agora seja consolidado em marcos normativos universais sobre o assunto, tamanha a dimensão do consumidor no cenário mundial e a propagação dos abusos nesse ambiente.

\section{REFERÊNCIAS}

ADORNO, Theodor. Indústria Cultural e Sociedade. São Paulo: Paz \& Terra, 2015.

ADORNO, HORKHEIMER. Dialética do Esclarecimento. Rio de Janeiro: Zahar, 1985.

ARENDT, Hannah. Entre o Passado e o Futuro. São Paulo: Perspectiva, 1972.

ARENDT, Hannah. A Condição Humana. Rio de Janeiro: Forense Universitária, 2010 .

BAUMAN, Zygmunt. A ética é possível num mundo de consumidores? Rio de Janeiro: Zahar, 2011.

BAUMAN, Zygmunt. Vida líquida. Rio de Janeiro: Zahar, 2009.

BAUMAN, Zygmunt. Vida para o consumo: a transformação das pessoas em mercadoria. Rio de Janeiro: Zahar, 2008.

BARBOSA, Fernanda; MULTEDO, Renata. Danos Extrapatrimoniais Coletivos. Revista de Direito do Consumidor, São Paulo, ano 23, v. 93, maio/jun 2014. 
BENJAMIN, Walter. Magia e Técnica, Arte e Política. Ensaios sobre Literatura e História da Cultura. São Paulo: Brasiliense, 1993.

BENJAMIN, Antônio Herman; MARQUES, Cláudia Lima. Extrato do Relatório-Geral da Comissão de Juristas do Senado Federal para atualização do Código de Defesa do Consumidor. Revista de Direito do Consumidor, São Paulo, ano 23, v. 93, maio/ jun. 2014.

BUJOSA VADELL, Lorenzo. La protección jurisdicional de los intereses de grupo. Barcelona: José María Bosh, 1995.

DEBORD, Guy. La Sociedad del Espetáculo. Valencia: Pré-Textos, 2007.

DE LUCCA, Newton. Direito do Consumidor. São Paulo: Quartier Latin, 2003.

GATTI, Luciano. Theodor W. Adorno: Indústria Cultural e Crítica da Cultura. In: NOBRE, Marcos (Org.). Curso Livre de Teoria Crítica. Campinas: Papirus, 2008.

HOMERO. Odisseia. São Paulo: Martin Claret, 2005.

JIMENEZ, Marc. Para ler Adorno. Rio de Janeiro: Livraria Francisco Alves, 1977.

MARCUSE, Hebert. El Hombre Unidimensional. Barcelona: Seix Barral, 1972.

MARQUES, Cláudia Lima. A proteção dos consumidores em um mundo globalizado: Studium Generale sobre o consumidor como Homo Novus. Revista de Direito do Consumidor, São Paulo, ano 22, v. 85, jan./fev. 2013.

PALHARES, Taisa. Walter Benjamin, Teoria da Arte e Reprodutibilidade Técnica. In: NOBRE, Marcos (Org.). Curso Livre de Teoria Crítica. Campinas: Papirus, 2008.

SELIGMANN-SILVA, Márcio. A Atualidade de Walter Benjamin e de Theodor W. Adorno. Rio de Janeiro: Civilização Brasileira, 2010.

TERRA, Ricardo. Hebert Marcuse. Os limites do paradigma da revolução: ciência, técnica e movimentos sociais. In: NOBRE, Marcos (Org.). Curso Livre de Teoria Crítica. Campinas: Papirus, 2008. 
Recebido em: 24 de maio de 2016 Aceito em: 21 de dezembro de 2016 